Journal of Applied Fluid Mechanics, Vol. 15, No. 2, pp. 603-615, 2022.

Available online at www.jafmonline.net, ISSN 1735-3572, EISSN 1735-3645.

https://doi.org/10.47176/jafm.15.02.32959

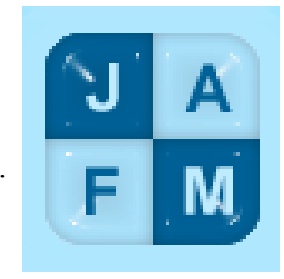

\title{
Study of the Behavior of a Vertical Axis Eolic Turbine with Articulated Blades
}

\author{
R. G. Ramirez Camacho ${ }^{1 \dagger}$, W. D. Suárez ${ }^{1}$, G. L. Tiago Filho ${ }^{1}$, D. Cardoso Netto ${ }^{1}$, \\ L. Fortes Miranda ${ }^{1}$ and G. Vasconcelos ${ }^{2}$ \\ ${ }^{1}$ Federal University of Itajubá, Av. BPS, 1303, Pinheirinho, Itajuba, 37500-015, Minas Gerais, Brazil \\ ${ }^{2}$ Energy Matrix Company - Itajubá-Mg-Brazil \\ $\dagger$ Corresponding Author Email: ramirez@unifei.edu.br
}

(Received May 3, 2021; accepted November 5, 2021)

\begin{abstract}
This work presents the results of the development of a vertical axis wind turbine composed of variable geometry, plane blades, applied in operations with low wind speeds. The new concept of vertical axis wind turbine with variable opening blades is presented as an innovative prototype where mechanical details are important for the natural control of the openings of the blades. Theoretical, numerical and experimental analyzes are performed in the turbine called DEC ${ }^{\circledR}$ with the aim of determining the aerodynamic characteristics. An analysis of the behavior of the DEC ${ }^{\circledR}$ turbine consists of a numerical study carried out to calculate or drag coefficient, considering a range of opening positions of the opening at each moment to determine the power coefficient. A second numerical approach is to analyze the moment caused by the interaction between all the turbine blades, in which the effects of energy dissipation caused by the flow mats are considered. Then, the theoretical, numerical results are validated by tests performed using a model in the open wind tunnel, where the prototype is subjected to different wind speeds while maintaining rotation control. Suggestions are made to improve the mechanical and aerodynamic design of the innovative prototype. Finally, the DEC® turbine is expected to serve as an inspiration for creating other mechanical forms of passive or active control to improve variable aerodynamics applied in low-speed conditions.
\end{abstract}

Keywords: VAWT; Articulated blade; CFD; Experimental test; Power coefficient.

\section{NOMENCLATURE}

$\begin{array}{ll}A_{P} & \text { project area } \\ C_{d} & \text { drag coefficient } \\ C_{\mathrm{p}} & \text { power coefficient } \\ \mathrm{c}_{\mathrm{g}} & \text { center of gravity } \\ F_{\theta} & \text { tangential force } \\ \mathrm{DEC} \otimes & \text { Dulcetti Energy Converted } \\ \mathrm{TSR}, \lambda & \text { Tip Speed Ratio }\end{array}$

\section{INTRODUCTION}

Vertical axis wind turbines, as Savonios and Darrieus $\mathrm{H}$, were and widely study with the objective of increasing the power coefficient through new geometric con-figurations. However, the folding blade wind turbine presents itself as a new aerodynamic concept to be studied and optimized. In the literature, similar works have not yet been reported that present results for the analysis of aerodynamic behavior, being necessary to present first a theoretical analysis to understand the physical phenomenon based on the equations of amount of

$\begin{array}{ll}\text { VAWT } & \text { Vertical-Axis Wind Turbine } \\ \mathrm{W} & \text { relative velocity } \\ \Omega & \text { angular velocity } \\ k & \text { kinetic energy } \\ \varepsilon & \text { energy dissipation } \\ \omega & \text { vorticity }\end{array}$

movement, a numerical analysis and finally, the experimental tests.

Theoretical, numerical and experimental analysis is presented to determine the torque of a vertical axis wind turbine with articulated blades. The theoretical and numerical approaches have to consider two degrees of freedom, i.e. the turbine angular motion and the blade sheets angular movement.

The first theoretical analysis was made for determinate the power coefficient based on the classical momentum and energy equations considering the losses associated with the energy 
dissipation due to shear stress and separation of the boundary layer through the calculation of the drag coefficient using numerical solutions (CFD) for different blade opening angles and different incidence velocities wind.

In the second numerical part (3D), are considered all rotational positions to determine the torque and the power coefficient carrying into account all 8 blades, thus accounting for all mechanisms of the energy dissipation generated by the interaction aerodynamics flow between the rotor blades. In this session, the CFD model and simulations are described.

In the third approach, an experimental bench test was set up to evaluate the operational characteristics of the prototype rotor DEC ${ }^{\circledR}$. Test methodology and details instrumentation are also presented in this paper with the aim that both numerical and experimental parts may be reproduced by other researchers considering the complex aerodynamic mechanism of motion. The bench test results are compared with commercially available wind technologies, succinctly describing the experimental and numerical results for the present VAWT in order to compare the DEC ${ }^{\circledR}$ with existing turbines and, from the conclusions, show recommendations for future projects.

\subsection{Practical Differences of Wind Turbine Type}

Wind turbines with high TSR can be horizontal axis rotor structures, with have higher $C_{p}$ than impulse rotors. The theoretical aerodynamics and design of horizontal- axis wind turbine is widely known in the literature (Letcher 2017; Manwell et. al 2009). Regarding of the vertical axis wind turbine (VAWT) has advantages given its simple de-sign easier to construct and transport and can easily be installed onsite. It requires a relatively small land area for installation and therefore is more suitable for urban use. It also has lower initial installation costs than horizontal axis wind turbines. The VAWT is omnidirectional and therefore does not need to track the wind direction and can operate in turbulent wind conditions with abrupt changes in wind direction. Since the generator can be installed at the base of the tower, it has low maintenance costs compared with horizontal axis wind turbines. If designed in smaller dimensions, it can be more easily used for distributed micro generation, domestic use, or in trade or small businesses (Ferrari et al. 2017) VAWTs have low TSR, also called $\lambda$, with power coefficients around 0.30 to 0.35 , lower than exhibited by horizontal axis wind turbines. They are limited in terms of power as they cannot self-start, requiring a small motor to start. Therefore, the development of new wind turbine concepts addressed to solve issues as selfstart ability and a low power generation is necessary.

\subsection{Wind Turbine with Folding Articu- lated blades, Dulcetti Eolic Converter - DEC ${ }^{\circledR}$}

The drag-induced types of VAWT, such as Savonius, are very robust, simple to design and to build.
However, it has a substantial flaw in the design: the torque suitable for transformation in energy is the positive torque that occurs at halfway wind blade revolution of the advancing blade. When a blade is retreating, i.e., it moves against the wind, it actually carries negative torque and therefore reduces the liquid torque applied to the generator and the resulting power generated. In this sense, the DEC ${ }^{\circledR}$ turbine with its articulated blade system would reduce the negative torque and control the positive torque in the mechanical system.

The main characteristic of the DEC® turbine consists of folding articulated blades composed of flat plates. These plates are alternately opened and closed according to the action of the wind that acts on the turbine, maximizing the action of the thrust force. When the blades are facing wind direction the plates are opened, producing turbine rotation, and when they move in the opposite direction, they are closed minimizing the opposite drag to the rotating motion of the turbine. Fig.1a shows the system of small gears that make it possible to open the blades symmetrically, the Fig. $1 \mathrm{~b}$ shows the fold of the blade that allows the aerodynamic control, Fig.1c, show complete prototype with 16 blades. The DEC $\mathbb{R}$ prototype was tested computationally and in an open wind tunnel in order to analyze the technical feasibility of this type of mechanism. There is a vast amount of literature about vertical axis wind turbines, however, studies with an articulating plane blade are few reported as Qasim et al. (2011).

Hui et al. (2018) highlighted that the academic focus has been the horizontal axis wind turbines, leaving out vertical wind turbines, and according to the authors, there may be rotor efficiency gains by arranging them in a cluster (in agglomerates), although to a lesser extent in urban cases, where this type of turbine can be quite adequate with minor risk of damage caused to birds. For example, the DEC ${ }^{\circledR}$ turbine can be easily installed on top of buildings or residential houses.

Lee et al. (2016) studied the effect of blade twist angle on the power coefficient of a Savonius wind turbine, twist angles of $0,45,90$ and 135 were evaluated, $k-\varepsilon$ RNG turbulence model was used. The greatest power coefficient values were found at tipspeed ratios ranging from $0.5-0.65$ for a twist angle of 45 degrees. The authors concluded that for twist angles greater than 90 degrees the power coefficient tended to stabilize.

McTavish et al. (2012) developed a novel vertical axis wind turbine consisting of several offseted vertically-stacked stages. $2 \mathrm{D}$ steady state and $3 \mathrm{D}$ simulations were conducted using CFD design 2010 and RNG k-epsilon turbulence model. Results exhibited a decrease in rotor torque fluctuations due to the usage of the vertically-stacked stages. Steady two-dimensional CFD simulations have demonstrated that the new VAWT has similar average static torque characteristics of existing Savonius rotors. Rotating three-dimensional CFD simulations were conducted at several tip speed ratios with a freestream speed of $6.0 \mathrm{~m} / \mathrm{s}$. The predicted dynamic torque generated by the rotor 
decays more rapidly with an increasing tip speed ratio than the torque output of Savonius rotors due to its asymmetric design and the curvature of the outer rotor wall. The modified Savonius rotor has greater positive torques with less variations when there is more than one rotor stacked on the vertical axis, but all parts of the rotor are fixed, that is, there is no variable geometry.

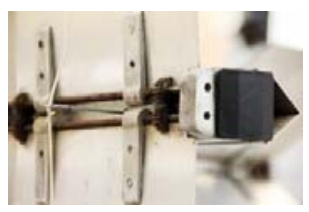

(a)

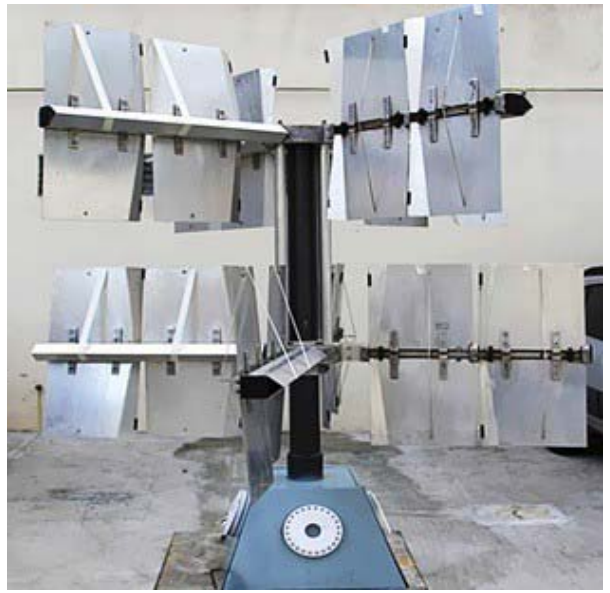

(c)

Fig. 1. VAWT idealized by DulcettiDEC®:, blade size, physical model used for computational modeling and for testing on the test bench.

Bhutta et al. (2012) presented a work on vertical axis turbines, showing that this type of turbine has a promising market potential. They outlined the advantages and limitations of all models, especially the Darrieus and Savonius wind turbines with all existing variations among them. In the article they showed that these turbines are feasible for several reasons, the biggest available wind potential, fast return on investment, and maximized power.

Qasim et al. (2011) presented the results of a vertical wind turbine with movable blades developed by Swamidass, which was designed to reduce the negative torque when moving against the wind. The results were a power coefficient on the order of 0.12 . The author concluded that the device could be used worldwide due to its high efficiency, simple construction, and simple technology.

Kumar et al. (2018) analyzed the behavior of different types of wind turbines for urban use and concluded that further research was needed to make VAWTs a viable, reliable and affordable energy generation technology for many low-energy and decentralized applications.

\section{Methodology}

\subsection{Theoretical-Numerical Approach for Power Coefficient.}

Based on unidimensional momentum equations it is possible to obtain a preliminary theory for VAWT torque analysis, assuming hypothesis such as incompressible flow, steady state, frictionless, wind pressure equally distributed over the blade sheets, with infinitesimal thickness, linear relation between blade opening and rotor angle and assuming that the kinetic energy transferred for the blade from closed to opened position $\left(0^{\circ}\right.$ to $\left.90^{\circ}\right)$ is equal to opened to closed $\left(90^{\circ}\right.$ to $\left.180^{\circ}\right)$.

Figure 2 shows in perspective view the blade movement from its all-closed position to the allopened, $\theta=0$ to $\theta=\pi / 2, \theta$ being the blade opening angle at a generic blade position. Therefore, the blade projected area $A p$ can be expressed as a function of the opening angle $\theta$ as $A p=\mathrm{a} . \mathrm{b}(\sin 2 \theta)$.

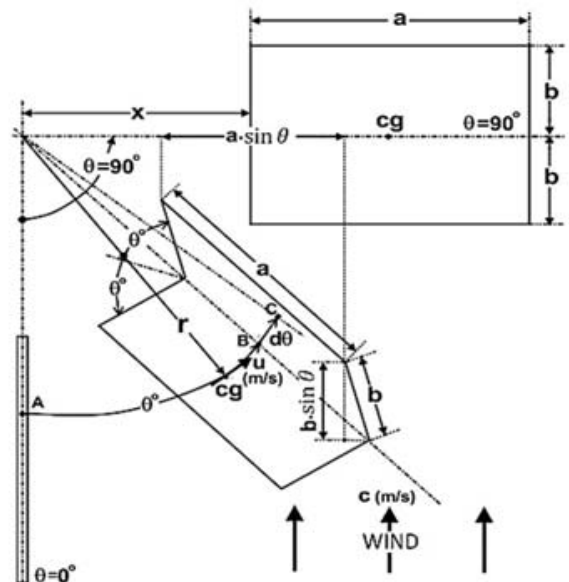

Fig. 2. Perspective view of blade movement.

Starting from energy conservation equation, disregarding losses and considering potential energy as zero, it can be inferred, theoretically, that all kinetic energy per unit mass of air flow $V^{2} / 2[\mathrm{~J} / \mathrm{kg}]$ that hits the blade is absorbed as pressure energy $p / \rho$ $[\mathrm{J} / \mathrm{kg}]$ equally distributed over the blade sheet length, $p_{1} / \rho+V_{1}^{2} / 2=0$.

Thus, the resulting force $F_{\theta 1}$, considering the viscous losses and acting on the center of pressure, whenever it overlaps with the center of gravity, $\mathrm{c}_{\mathrm{g}}$, can be determined by Eq. (1):

$F_{\theta 1}=\frac{1}{2} \rho C_{d} V_{\infty}^{2} A_{p}$

Considering that this type of turbine generates torque by transforming wind energy into acting pressure over the blades via drag, therefore it is necessary to determine the drag coefficient in order to calculate the torque. This way, it is possible to determine the drag coefficient, numerically to all ranges of blade opening angles and wind velocities (Fluent $\left.{ }^{\circledR}\right)$. Thus, 


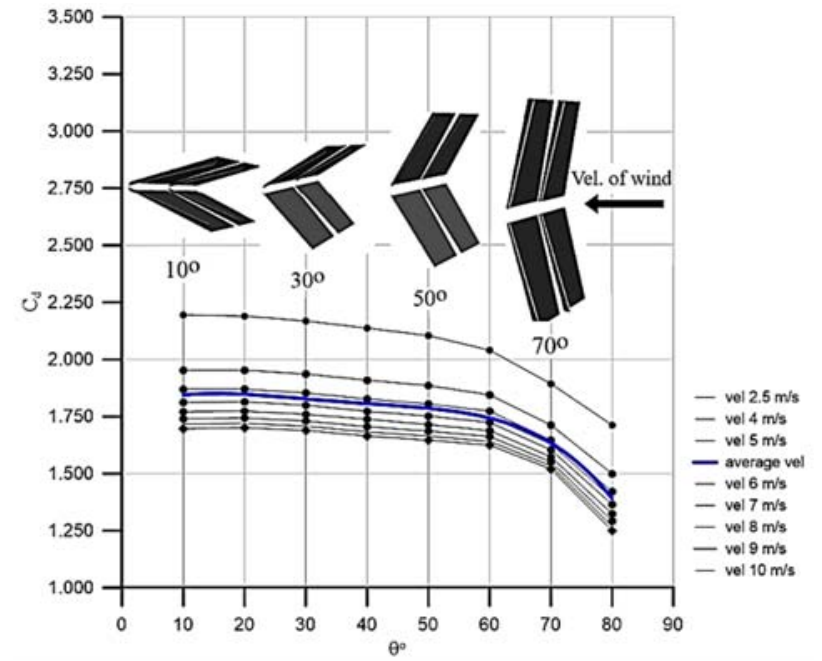

Fig. 3. Blade opening angle vs. drag coefficient for a range of wind velocity values.

numerical simulations were carried utilizing an inertial domain, $k-\omega$, SST turbulence model with standard wall-function and $y+$ values close to 5 , with 8 prismatic layers elements near the wall (Antonini et al. 2016).

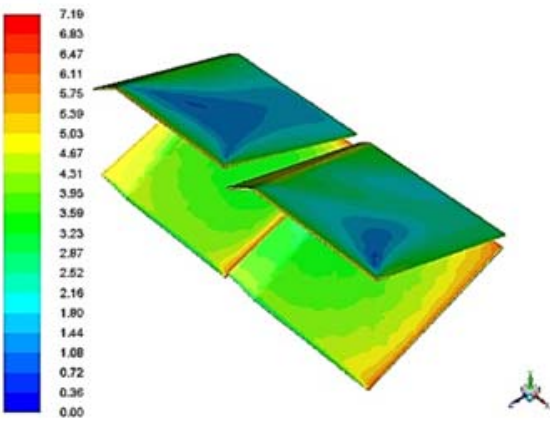

(a)

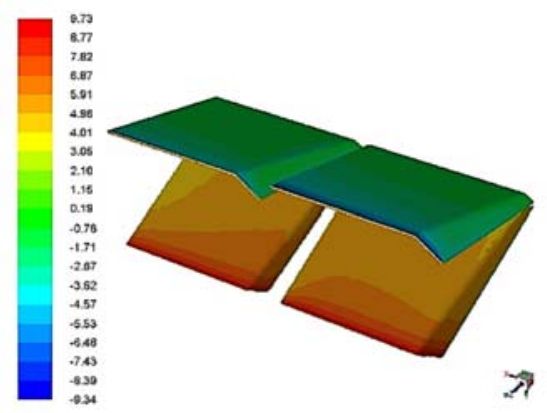

(b)

Fig. 4. (a) Contours of $y^{+}$values, (b) Contour of total relative pressure.

The Fig. 3 shows the results with blade opening angle variations and corresponding drag coefficient for each wind velocity. The blue line represents an interpolated average of drag variation approximated by the function, Eq.(2). The Fig. 4a-b, shows the contours of the $\mathrm{y}^{+}$and total pressure, using software Fluent ${ }^{2}$.

$$
C_{d}=a+b \theta+c \theta^{2}+d \theta^{3}+e \theta^{4} ; \theta[\mathrm{rad}],
$$

where, $a=1.77226 ; b=0.72429 ; c=-2.19855 ; d=$ 2.46597; $e=-1.00487$.

Considering the projected area variation, the tangential force can be calculated as:

$$
F_{\theta 1}=\rho a b \frac{V_{\infty}^{2}}{2} \sin ^{2} \theta
$$

Where the size of each blade is given by: $a=0.265 \mathrm{~m}$ and $b=0.250 \mathrm{~mm}$, with reference to Fig 5 . The projected area with 4 blades can be approximated to $\mathrm{AxB}=0.6448 \mathrm{~m}^{2}$.

It should be noted that it is complicated to define a single projected area because there are variations in the projection at different angular positions.

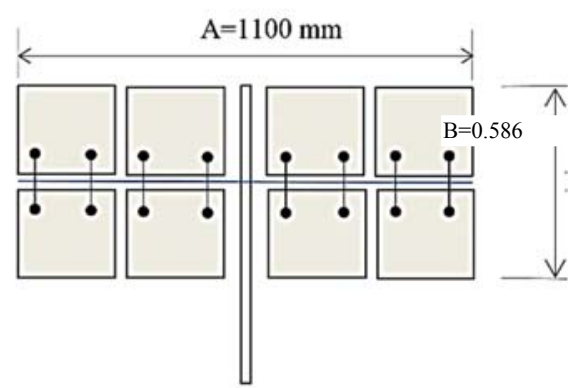

Fig. 5. Project area $A_{p}$.

The torque generated by the blade is obtained simply by multiplying the tangential force by the distance to the rotation axis, represented as $r$ in Fig. 6 . 


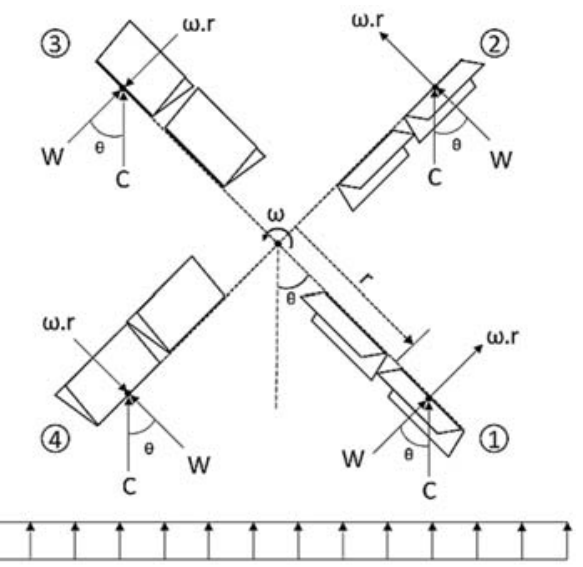

Fig. 6. Turbine scheme at a generic position, $\theta$.

The accountable velocity for the drag force is a result of the vector sum of the velocities acting on tangential direction, showed in Fig. 6. This way, the torque generated by each blade can be calculated, considering the relative velocity component.

$$
\begin{aligned}
& T_{1-2}=\frac{1}{2} \rho r(W+\omega r)^{2} 4 a b \sin ^{2} \theta(a+b \theta+ \\
& \left.+c \theta^{2}+d \theta^{3}+e \theta^{4}\right) \\
& T_{3-4}=\frac{1}{2} \rho r(W-\omega r)^{2} 4 a b \sin ^{2} \theta(a+b \theta+ \\
& \left.+c \theta^{2}+d \theta^{3}+e \theta^{4}\right) \\
& T_{\text {total }}=T_{1}+T_{2}-T_{3}-T_{4} \\
& C_{p}=\frac{M \Omega}{\frac{1}{2} \rho V^{3}(2 r+2 a)} .
\end{aligned}
$$

\subsection{Theoretical-Numerical Results}

Figure 7 shows the behavior of torque vs. theta ranging from 0 to $\pi / 2$. As noted, torque varies from a maximum value of $20.91 \mathrm{~N}-\mathrm{m}$ for $\theta=0$, when blade 2 is fully opened, to the same maximum value for $\theta=\pi / 2$, when blade 1.0 is fully opened, average torque of $16.02 \mathrm{~N}-\mathrm{m}$ is obtained.

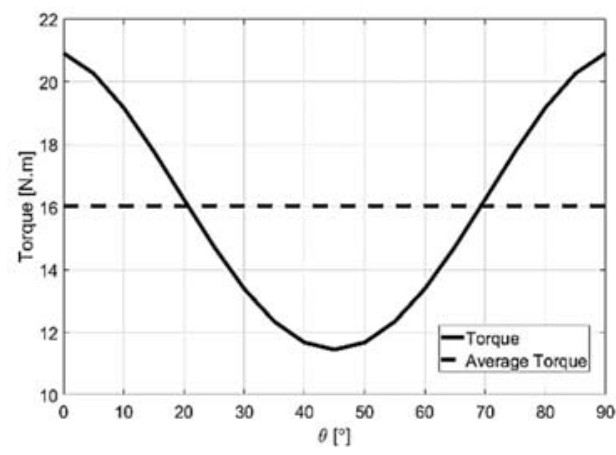

Fig. 7. Torque vs. theta at wind velocity of $\mathbf{1 1}$ $\mathbf{m} / \mathbf{s}$.

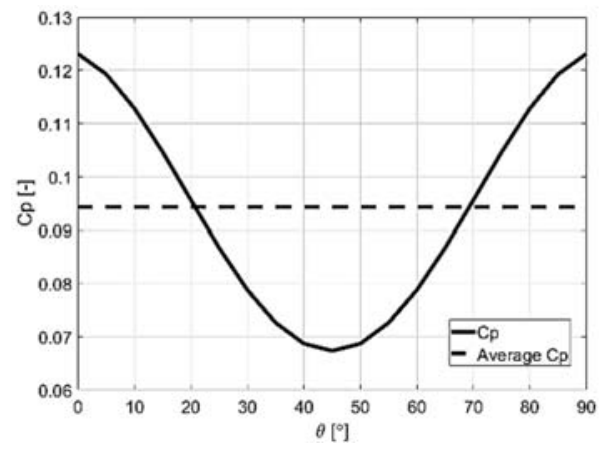

Fig. 8. $C_{p}$ vs theta at wind velocity of $11 \mathrm{~m} / \mathrm{s}$.

This first theoretical-numerical analysis allows to evaluate the torque and power coefficient characteristics for the DEC $($ turbine. In addition to this analysis, a flow field analysis representing the turbine with its 4 blades composed of 4 sheets each was also conducted.

Figure 8 , graphs of average values of the power coefficient are obtained with reference to the intensities of wind speed and rotation based on the experimental data, which will be seen in the subsequent sections.

\section{DEC ${ }^{\circledR}$ TURBINE CFD SIMULATION}

Problems of fluid mechanics in turbomachines are characterized by physical principles that are represented by conservation equations, in this case, only the mass and momentum conservation equations for inertial systems will be considered, defined as:

$\frac{\partial u_{i}}{\partial x_{i}}=0$

$\rho u_{k} \frac{\partial u_{j}}{\partial x_{k}}=-\frac{\partial}{\partial x_{j}}\left(p^{*} \delta_{i j}\right)+\mu \frac{\partial}{\partial x_{i}}\left(\frac{\partial u_{j}}{\partial x_{i}}+\frac{\partial u_{i}}{\partial x_{j}}\right)$

Where: $\rho$ : specified fluid mass, $u_{i}$ : absolute velocity, $p^{*}$ : moving static pressure, $\mu$ : dynamic viscosity.

For the determination of the Reynolds-averaged Navier Stokes equations for incompressible flow the system of Eq.(8) and (9), are decomposed in an average value plus a component of temporal fluctuation $u(t)=U+u^{\prime}(t)$. Thus, for a stationary, incompressible and Newtonian fluid, one can obtain the Reynolds equation in Einstein's notation in cartesian coordinates, such as:

$$
\begin{aligned}
& \rho \vec{u}_{i} \frac{\partial \vec{u}_{i}}{\partial x_{i}}= \\
& \quad \frac{\partial}{\partial x_{j}}\left[-\vec{p}^{*} \delta_{i j}+\mu\left(\frac{\partial \vec{u}_{i}}{\partial x_{j}}+\frac{\partial \vec{u}_{j}}{\partial x_{i}}\right)-\rho \vec{u}_{i}^{\prime} \vec{u}_{j}^{\prime}\right]
\end{aligned}
$$

On the other hand, according to Boussinesq's hypotheses, it is possible to relate the Reynolds stresses through the turbulent viscosity and the mean rates of deformation, given by: 
R. G. Ramirez Camacho et al. / JAFM, Vol. 15, No. 2, pp. 603-615, 2022.

$-\rho \vec{u}_{i}^{\prime} \vec{u}_{j}^{\prime}=\mu_{t}\left(\frac{\partial \vec{u}_{i}}{\partial x_{j}}+\frac{\partial \vec{u}_{j}}{\partial x_{i}}\right)-\frac{2}{3} \rho k \delta_{i j}$,

where, $k=1 / 2\left(\vec{u}_{1}^{\prime 2}+\vec{u}_{2}^{2}+\vec{u}_{3}^{2}\right)$ is the turbulent kinetic energy per unit mass and $\mu_{\mathrm{t}}$ is the eddy viscosity. There is also a kinematic turbulent denoted by $v=\mu_{t} / \rho$ with dimensions $\mathrm{m}^{2} / \mathrm{s}$.

To close the system of equations, it is necessary to determine the turbulent viscosity, being this modeled using other scalar transport equations such as for example: $k-\varepsilon$ and $k-\omega$.

\section{$\underline{\text { Wilcox } k \text { - } \omega \text { model }}$}

The $k-\omega$ turbulence model is also based on two scalar transport equations, in which dissipation term is calculated based on vorticity. The model proposed by Wilcox $(1998,1993,1994)$, uses the turbulence frequency $\omega=\varepsilon / k\left(\mathrm{~s}^{-1}\right)$ and the length scale is $\ell=k^{3 / 2} / \varepsilon$. The eddy viscosity is given by turbulent viscosity, defined as: $\mu_{t}=\rho k / \omega$, Thus, the new equations for $k$ and $\omega$ are:

$$
\begin{gathered}
\frac{\partial(\rho k)}{\partial t}+U_{j} \frac{\partial(\rho k)}{\partial x_{j}}=\frac{\partial}{\partial x_{j}}\left(\left(\mu+\frac{\mu_{t}}{\sigma_{k}}\right) \frac{\partial k}{\partial x_{j}}\right)+ \\
+\left(2 \mu_{t} S_{i j} \cdot S_{i j}-\frac{2}{3} \rho \omega \frac{\partial U_{i}}{\partial x_{j}} \delta_{i j}\right)-\beta^{*} \rho k \omega \\
\frac{\partial(\rho \omega)}{\partial t}+U_{j} \frac{\partial(\rho \omega)}{\partial x_{j}}=\frac{\partial}{\partial x_{j}}\left(\left(\mu+\frac{\mu_{t}}{\sigma_{\omega}}\right) \frac{\partial \omega}{\partial x_{j}}\right)+ \\
+\gamma_{1}\left(2 \rho S_{i j} \cdot S_{i j}-\frac{2}{3} \rho \omega \frac{\partial U_{i}}{\partial x_{j}} \delta_{i j}\right)-\beta_{1} \rho \omega^{2} \\
S_{i j}=\left(\frac{\partial U_{i}}{\partial x_{j}}+\frac{\partial U_{j}}{\partial x_{i}}\right)
\end{gathered}
$$$$
\sigma_{k}=2.0, \sigma_{\omega}=2.0, \gamma_{l}=0.553, \beta_{l}=0.075, \beta^{*}=0.09
$$

\section{Menter $k-\omega$ SST model}

There is a combination of $k-\varepsilon$ and $k$ - $\omega$ models resulting in $k-\omega$ SST model, with the advent of Shear Stress Transport (SST) methodology. This model was initially proposed by Menter (1994) with the purpose of modeling turbulence with variation of pressure gradient and separation of boundary layer (Launder and Spalding 1974).

Thus, fundamental equations of this model are presented, turbulence kinetic energy is represented by $\mathrm{Eq}(12)$ and new equation for specific dissipation rate:

$$
\begin{array}{r}
\frac{\partial(\rho \omega)}{\partial t}+U_{j} \frac{\partial(\rho \omega)}{\partial x_{j}}=\frac{\partial}{\partial x_{j}}\left(\left(\mu+\frac{\mu_{t}}{\sigma_{\omega, 1}}\right) \frac{\partial \omega}{\partial x_{j}}\right)+ \\
+\gamma_{2}\left(2 \rho S_{i j} S_{i j}-\frac{2}{3} \rho \omega \frac{\partial U_{i}}{\partial x_{j}} \delta_{i j}\right)- \\
-\beta_{2} \rho \omega^{2}+2\left(1-F_{1}\right) \frac{\rho}{\sigma_{\omega, 2} \omega} \frac{\partial k}{\partial x_{k}} \frac{\partial \omega}{\partial x_{k}}
\end{array}
$$

$\sigma_{k}=1.0, \sigma_{\omega l}=2.0, \quad \sigma_{\omega 2}=1.17, \quad \gamma_{2}=0.44, \quad \beta_{2}=0.083$, $\beta^{*}=0.09$

In the last term of Eq. (15), the term $F_{1}$ is introduced for turbulence model $k$ - $\omega$ SST. Menter (1994) defines regions close to wall as $F_{1}=1$ and, for regions away from the wall, as $F_{1}=0$. If $F_{1}=0$ the Eq.(15) is transformed is the equation for turbulence dissipation $\varepsilon$ using the relation $\omega=\varepsilon / k$. However, when there is a mesh, which it has three regions (close to the wall, away from the wall and the central region), it is possible to obtain a weight function to define the central region through the argument of the hyperbolic tangent function $(\tanh )$, with a slight variation between limits of 0 and 1, as shown in Fig. 9.

Variable $d$ in Eq. (16) represents the perpendicular distance between wall and nodal point of element or control volume, so that in each nodal point function of argument are calculated and evaluated according to maximum and minimum functions. On the other hand, the constants of $k-\varepsilon$ and $k-\omega$ models, are calibrated through the mixing functions, $\phi=F_{1} \phi_{\omega}+\left(1-F_{1}\right) \phi_{s}$, if $F_{1}=1$, so $\phi=\phi_{\omega}$ that implies the use of the k- $\omega$ model by introducing the constant $\beta^{*}$. If $F_{1}=0$, so $\phi=\phi_{s}$ that implies the use of the k- $\varepsilon$ model with the constant $C_{\mu}$, defined as: $\varepsilon=C_{\mu} k \omega$.

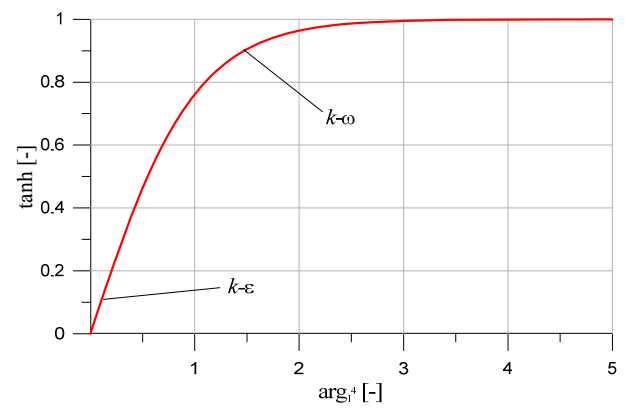

Fig. 9: Function $F_{1} \tanh \left(\arg _{1}^{4}\right)$

$$
\begin{aligned}
& \arg _{1}=\min \left[\max \left(\frac{\sqrt{k}}{\beta^{*} \omega d}, \frac{500 v}{d^{2} \omega}\right), \frac{4 \rho \sigma_{\omega 2} k}{C D_{k \omega} d^{2}}\right] \\
& C D_{k \omega}=\max \left[\left(2 \rho \frac{1}{\sigma_{\omega 2} \omega} \frac{\partial k}{\partial x_{j}} \frac{\partial \omega}{\partial x_{j}}, 1.0 E^{-10}\right)\right]
\end{aligned}
$$

Eddy viscosity is limited to give improved performance in flows for adverse pressure gradients and wake regions. In this sense, the turbulent kinetic energy production is limited to prevent the build-up of turbulence in stagnation regions. Limiters are as follows.

$$
\begin{aligned}
& \mu_{t}=\frac{5 / 9 \rho k}{\max \left(\frac{5}{9} \omega, \sqrt{2 S_{i j} S_{i j}} F_{2}\right)} \\
& F_{2}=\tanh \left[\left(\max \left(\frac{2 \sqrt{k}}{\beta^{*} \omega d}, \frac{500 v}{d^{2} \omega}\right)\right)^{2}\right]
\end{aligned}
$$


Turbulent kinetic energy production term now is evaluated by the minimization function as:

$$
P_{k}=\min \left(10 \beta^{*} \rho k \omega, 2 \mu_{t} S_{i j} S_{i j}-\frac{2}{3} \rho k \frac{\partial U_{i}}{\partial x_{j}} \delta_{i j}\right)
$$

The k- $\omega$ SST model gives better agreement with experiments of mildly separated flow. This is primarily due the viscosity limiter. Hence, this model is appropriate for external e internal flows, an example the flow in the periodic hydraulic channel.

The turbulence model adopted was the $k-\omega \mathrm{SST}$, with wall functions to quantify the turbulent viscosity (Menter 1994).

The SIMPLE method was used as a coupling technique between pressure and velocity. For the numerical schemes for the pressure, the Standard and First-Order Upwind methods were used to the convection term. Relaxation factors were adopted for the momentum and for turbulent kinetic energy of 0.4 and 0.5 respectively. Residuals were monitored at $10^{-4}$ for the momentum components and $10^{-3}$ for $k$ and $\omega$. Global variations in static pressures at the inlet and outlet regions of the domain and mass flow were also monitored.

\subsection{Geometry and Mesh Grid Generation}

The wind turbine geometry is characterized by a system of flat panels with horizontal rods that rotate around a vertical axis to which variable-geometry blades are installed. They are composed of articulated plates that are simultaneously opened when facing the wind and closed when against it. The domain numerical modeling of the wind turbine (DECR) is shown in Fig. 10, for 8 sets of blades.

To analyze the flow, three domains in $3 \mathrm{D}$ were considered. The first, spherical domain that contains the DEC $($ turbine rotor, the second a domain for generating the wake and the third where the speed gradients tend to zero (Fig.10a).

Figure 6a shows a cross section of the mesh grid, the circle around the turbine represents the non-inertial domain that corresponds to the rotor region, and the outer region represents the inertial domain corresponding to the far field. For the calculation domain, the value of $10 \times$ Diameter downstream and 3 $X$ Diameter upstream were defined, this domain being appropriate considering studies in hydrokinetic and eolics turbines.

In principle, the domains were connected by interfaces with the sliding mesh condition to allow the rotor domain to rotate and the external domain to remain fixed. However, this approach was unconsidered because it would be necessary to add the opening movement of the blades, within a dynamic known as a movement by two degrees of freedom. Therefore, static analysis was performed with 10 different configurations at downstream flow to represent the dynamics considering the angular movement synchronized with the opening and closing system of the blades.

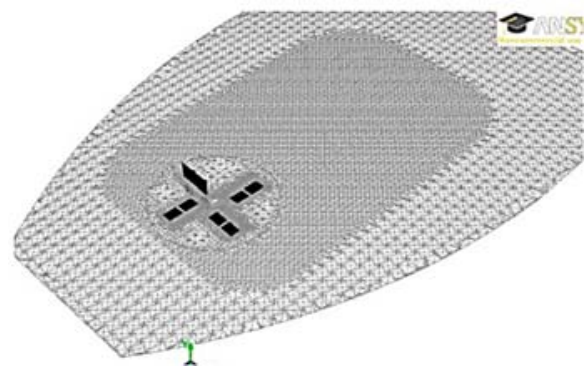

(a)

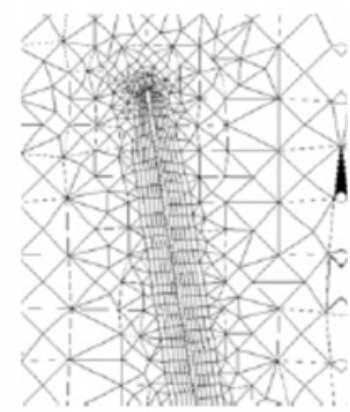

(b)

Fig. 10. (a) Detail of the mesh grid at nearblade region blade thickness $2 \mathrm{~mm}$, (b) cross section of the mesh grid, $\sim 8$ million elements.

The authors would like to clarify that the solution is in a steady state, that is, there is no temporal variation, the angular moment is defined instantly for each rotor position (see Fig. 11), due to the impossibility of simulating the two movements simultaneously, rotation and opening of the blades. On the other hand, however, not reported in the work, the rotational movement was performed for each opening position of the blades, considering 3 turns of the rotor and a step time of 0.01 , disregarding the pseudo transient, torque results did not represent consistent with experimental results measured instantly by the torquimeter in this sense the transient analysis was disregarded.

Remembering that our simulation is in steady-state, a script was edited in the TCL/TK language for interpretation of the ICEM -CFD software. The code or script generates the geometry of different opening and closing positions of the blades associated with the rotation movement as the Fig. 12. The script, besides generating the geometry, also generates the mesh with the adopted mesh control parameters. This technique, based on script commands is frequently used in optimizing processes.

Figures 10(b) show in detail the unstructured mesh used, composed mostly tetrahedrons, and the prismlayer region close to the blade surface with eight prismatic layers with a growth rate of 1.1. The thickness of the prismatic layers in the near-wall region were calculated based on the Reynolds number so that the $y+\approx 10$ and the velocity gradients are determined in the region following the viscous sub-layer. 
In the numerical analyses, it is important to verify that the solution is independent of the mesh, in this sense we used the torque value and the velocity of $10 \mathrm{~m} / \mathrm{s}$ as parameters. A reference mesh with 7,909,692 elements, 5 prismatic layers, resulted in torque of $10.403 \mathrm{~N}-\mathrm{m}$. A second mesh with greater refinement, $9,854,678$ elements, and 7 prismatic layers, resulted in a torque value of $10.295 \mathrm{~N}-\mathrm{m}$. Considering the suggestion according to LEAP CFD TEAM 2017, which defines as mesh independence criteria the relation: $\left[\left(\mathrm{T}_{\mathrm{z}, \text { ref }}-\mathrm{T}_{\mathrm{z} \text {,fine }}\right) / \mathrm{T}_{\mathrm{z} \text {,ref }}\right] \times 100 \leq 1 \%$. Then, applying, the torque, results in a value around $1 \%$, $(1.038 \%)$ being then considered the reference mesh is independent of the solution.

\subsection{Steady Simulations}

In order to obtain the behavior of the turbine for an entire revolution, the turbine rotation was divided into ten fixed positions, as shown in (Fig.11), allowing for a number of simulations with different geometries to be conducted. The torque is calculated at each position to characterize the DEC ${ }^{\circledR}$ turbine behavior. In Fig. 7, the end angular position of rotation of the axis is the 81 degrees, followed by the next position starting in zero degrees. Therefore, it is only necessary to simulate $1 / 4$ turn. In order to obtain similar meshes for each angular position a script was edited with commands in Tcl-Tk, for interpretation in the ICEM-CFD ${ }^{\circledR}$ software.

It is important to emphasize that the DEC $($ turbine exhibits regions of high separation at the boundary layer, where numerous vortex structures of different scales are emitted, thus, a non-permanent approach would be the most adequate one. However, considering the turbulence model $k-\omega$, SST it is possible to obtain the numerical solution in a stable way for the simulation in steady state.

It is noteworthy that although the problem presents high regions of separation of the boundary layers, there is a small gap between the blades that reduces the regions of stagnation of the flow, which makes it easier and stability the numerical solution in steady state.

The boundary conditions applied in the wind turbine analysis are such: imposition of wind speed component at the inlet and at the lateral surfaces. In the outlet is introduced the pressure-outlet condition with atmospheric pressure. The angular velocity of the rotor domain is no variable (constant) and the wind velocity is varied from 5 to $15 \mathrm{~m} / \mathrm{s}$ at the inlet and lateral surfaces, resulting in different tip-speed ratio values for each wind velocity, thus, allowing for the evaluation of the power coefficient curve as a function of TSR. The air density is $1.2 \mathrm{~kg} / \mathrm{m}^{3}$ and dynamic viscosity is $1.7894 \times 10-5 \mathrm{~kg} / \mathrm{m} . \mathrm{s}$.

\section{CFD SIMULATION RESULTS}

Figure 12 shows the variation of torque as a function of the opening blade angle. Larger variations are observed with speeds between 10 and $15 \mathrm{~m} / \mathrm{s}$, with nearly constant torque for the wind speed of $5 \mathrm{~m} / \mathrm{s}$. This wind turbine has a peculiar characteristic, the geometry is distinct at each one of the angular positions, therefore, the torque does not exhibit a periodic behavior commonly produced by other VAWT like Savonius and Darrieus. It can be noted that as the wind velocity $0^{\circ}$

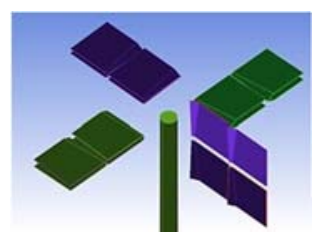

$18^{\circ}$

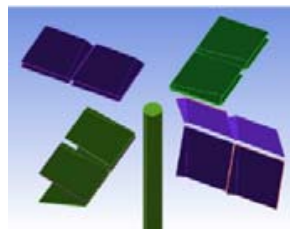

$36^{\circ}$

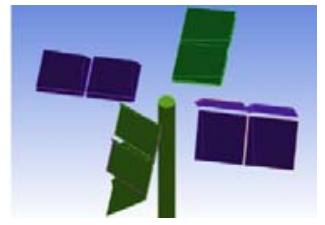

$54^{\circ}$

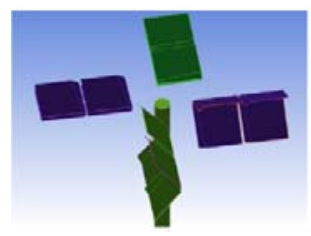

$72^{\circ}$

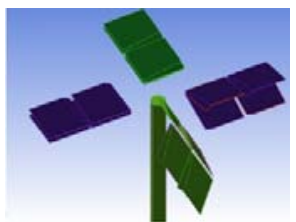

$9^{\circ}$

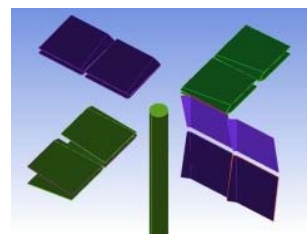

$27^{\circ}$

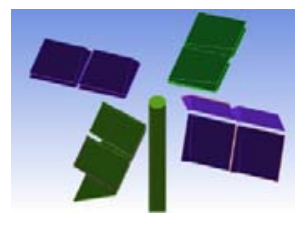

$45^{\circ}$

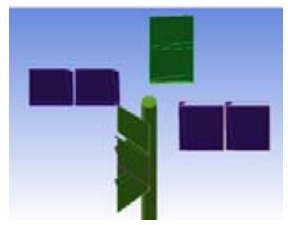

$63^{\circ}$

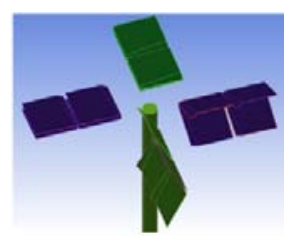

$81^{\circ}$

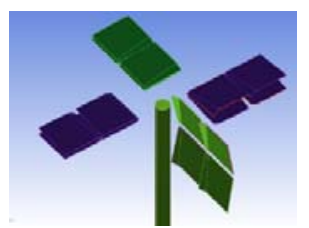

Fig. 11. Sequence of blade rotation and opening angles.

increases, there is decrease in the torque for the blade opening angles between 45 and 60 degrees, this range is critical for the turbine since at 45 degrees both blades that are against the wind are not fully opened and not as capable of extracting much energy from the wind. As the angle increases or decreases, there will always be a blade that is sufficiently opened to extract energy from the wind more efficiently.

Figure 13 shows the behavior of the streamlines at different blade opening angles and positions. It is observed the formation of regions of massive separation with highly intense turbulence. These large regions of vortex energy dissipation and massive separation certainly compromise the efficiency of the wind turbine. 


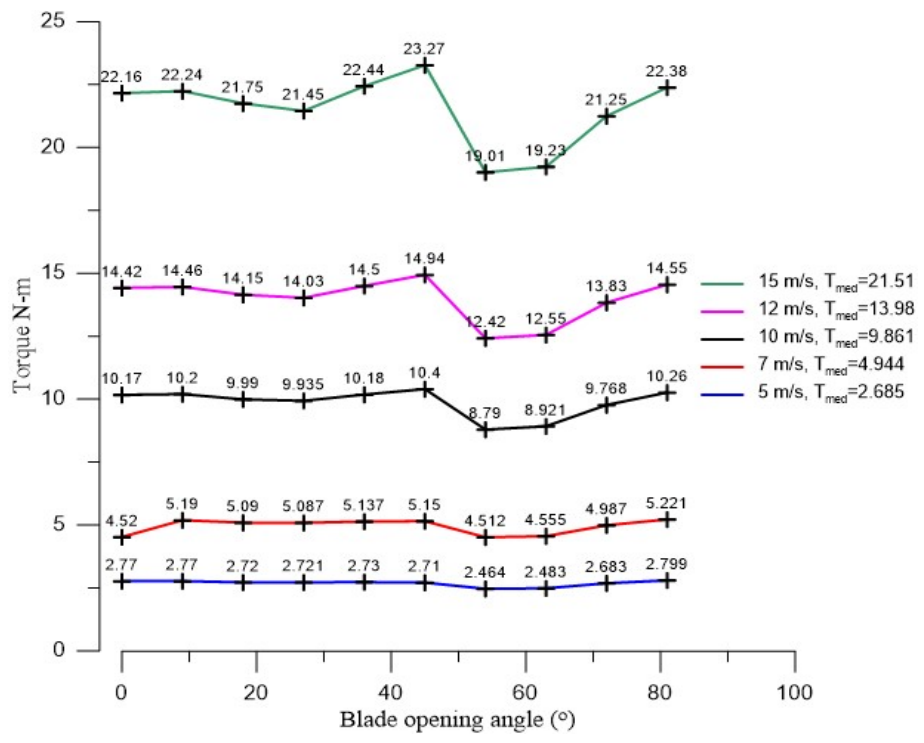

Fig. 12. Torque vs. blade opening angle $(\theta)$, with reference to the 10 positions (Fig. 11).

Figure 14 shows the behavior of the DEC $®$ turbine, where it can be observed that the best energy conversion occurs at lower wind speeds. At this point it is possible to calculate the power coefficient defined as:

$$
C_{p}=\frac{T_{z} \Omega}{0.5 \rho V_{\infty}^{3} A_{p}}
$$

On the other hand, it was verified that the power coefficient is lower with high wind speeds, which leads to the conclusion that the DEC ${ }$ turbine in this condition is highly dissipative, as a result, it is more suitable for low wind speeds. Besides, the CFD results for power coefficient were shown to be in good accordance with the power coefficient obtained by the theoretical approach as stated in section 2.1

Figure 14, there is a good agreement between the experimental and numerical results around $7.0 \mathrm{~m} / \mathrm{s}$, however, at low and high wind velocity the numerical and experimental values lose agreement, due to the flow being highly dissipative due to the interaction between blades, resulting in instabilities in the calculation or measurement of the experimental torque too. However, the behavior of the variations of the power coefficient as a function of wind speed is consistent with both approaches.

\subsection{Open Wind Tunnel Tests}

In order to obtain the main operational characteristics of the DEC $($ turbine and to validate the computational model used in Fluent-CFD ${ }^{\circledR}$, experiments were carried out with a reduced size model. The DEC® VAWT model built by Endicon was installed in the Open-Air Aerodynamic Test Platform located at the Federal University of Itajuba (UNIFEI) Campus. The wind turbine bench test setup shown in (Fig. 15) consisted of an axial fan powered by a three-phase $92 \mathrm{~kW}$ belt driven transmission, electric motor with a $220 \mathrm{~V}$ voltage rating and a rotational speed of $1800 \mathrm{rpm}$. The
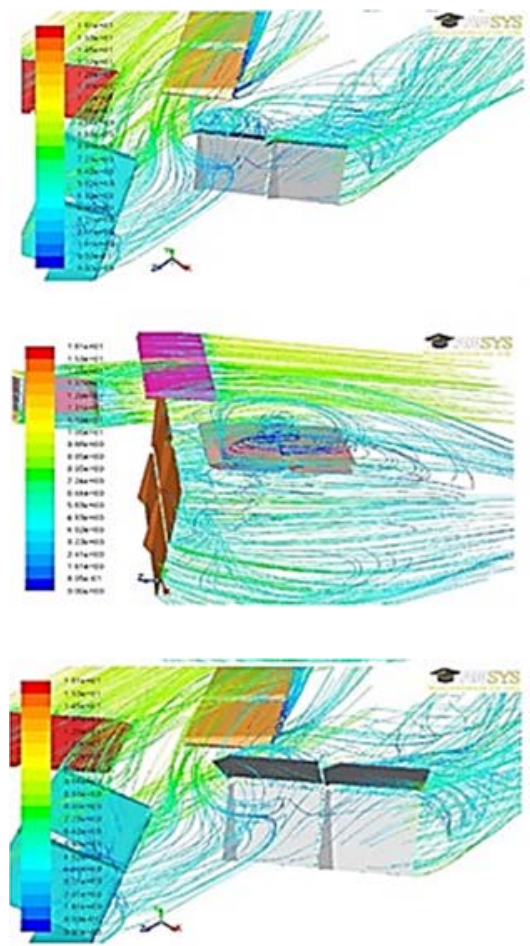

Fig. 13. Streamlines highlighting the separation regions in the DEC ${ }^{\circledR}$ rotor.

fan is installed inside of a duct that is 2.0 meters in diameter and 5.37 meters long. It is capable of simulating high intensity winds up to $15 \mathrm{~m} / \mathrm{s}$. A set of blades is positioned at the inlet section of the duct immediately downstream of the fan. The blade set can be adjusted by a lever allowing the inlet airflow to be controlled. A metallic cone-like structure is installed on the outlet section of the fan to act as a flow rectifier. 


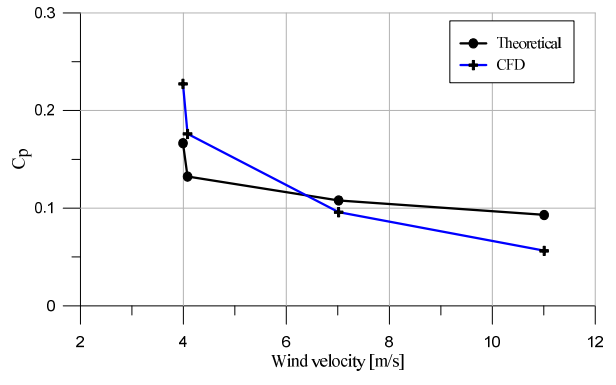

Fig. 14. $C_{p}$ vs. wind speed of the DEC ${ }^{\circledR}$ wind turbine obtained by numerical simulation and theoretical approach.
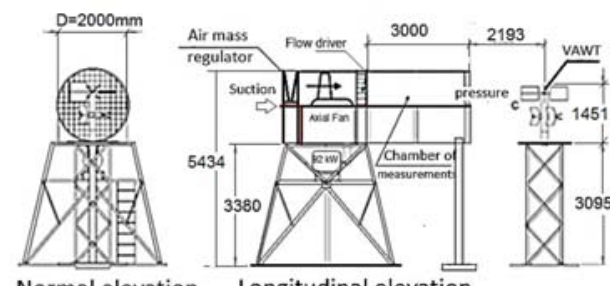

Normal ele
Plant
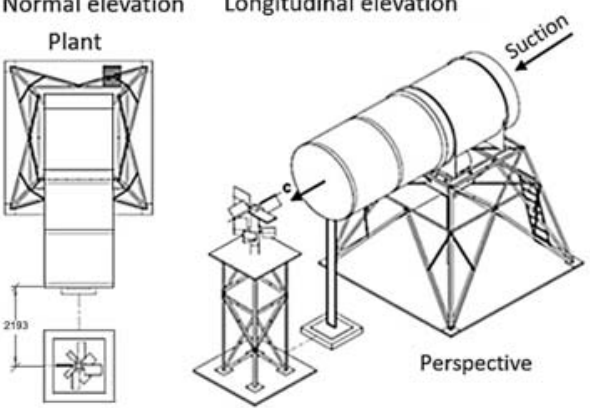

Fig. 15. Wind turbine bench test.

The test model was installed and aligned to the centerline of the fan duct on a metal platform 2.153 meters away from the outlet face of the air duct.

The axis of the wind turbine were connected to a torque meter that was connected to the axis of a pulley. The pulley drives the generator via a belt drive transmission. A variable resistance load controlled by a varivolt is connected to the generator.

The velocity data obtained via the Prandtl tube-probe anemometer was compared to the data obtained with a portable anemometer. Initially a maximum scan of $400 \mathrm{~mm}$ was used with Prandtl tube-probe. Tests showed that the Prandtl Tube located $350 \mathrm{~mm}$ from the wall resulted in more stable measurements and ensured that the magnitude of the measured velocity was close to the incident in the prototype.

Data on the wind velocity was obtained using a computer with Gill Instrument WindView ${ }^{\circledR}$ software. Data on torque was obtained with LabView ${ }^{\circledR}$. Calculations were performed in Excel, averaging the obtained values from two minutes for each point (average of 60 samplings per minute).

Table 1 presents the measuring instruments and their respective ranges and resolutions. All instruments were calibrated according to current standards. The average results obtained from the experimental test are shown in Table 2.

Table 1 - Information of range and resolution of the measuring instruments used in bench tests

\begin{tabular}{|l|l|l|}
\hline \multicolumn{1}{|c|}{$\begin{array}{c}\text { Measuring } \\
\text { instrument }\end{array}$} & $\begin{array}{c}\text { Measuring } \\
\text { range }\end{array}$ & \multicolumn{1}{|c|}{ Resolution } \\
\hline Sonic anemometer & $0.4-30 \mathrm{~m} / \mathrm{s}$ & $0.1 \mathrm{~m} / \mathrm{s}$ \\
\hline $\begin{array}{l}\text { Flexible } \\
\text { anemometer }\end{array}$ & $0.6-30 \mathrm{~m} / \mathrm{s}$ & $0.01 \mathrm{~m} / \mathrm{s}$ \\
\hline $\begin{array}{l}\text { Portable tachometer } \\
\text { Laser }\end{array}$ & $\begin{array}{l}1.5-99,999 \\
\mathrm{rpm}\end{array}$ & $\begin{array}{l}0.1 \mathrm{rpm}(2.5 \\
\text { to } 999.9 \mathrm{rpm}) ; \\
1 \mathrm{rpm}(>1000 \\
\mathrm{rpm})\end{array}$ \\
\hline $\begin{array}{l}\text { Thermometer } \\
\text { Pressure gauge (for } \\
\text { atmospheric } \\
\text { pressure) }\end{array}$ & $\begin{array}{l}795-1050 \\
\mathrm{mb}\end{array}$ & $1 \mathrm{mb}$ \\
\hline Moisture meter & $10-95 \%$ & $0.1 \%$ \\
\hline Torque sensor & $0-100 \mathrm{~N} \cdot \mathrm{m}$ & $1 \mathrm{~N} \cdot \mathrm{m}$ \\
\hline
\end{tabular}

\section{RESULTS AND DISCUSSIONS}

\subsection{Experimental Results}

The errors and uncertainties were calculated for the measured quantities using usual formulas (such as standard deviation). Propagation of errors was calculated for the indirect quantities, in this case the Student's t-distribution is considered with a probability of success of $95 \%$. These values were calculated using the software LabView ${ }^{\circledR}$ and Excel®. Applying these traditional equations, an error for the $C_{p}$ in the order of $3 \%$ was obtained.

The limiting conditions for the test were: for a low wind speed of less than $3.5 \mathrm{~m} / \mathrm{s}$ the model remained static and from speeds above $12 \mathrm{~m} / \mathrm{s}$ the wind turbine was damaged, resulting in broken cables responsible for limiting blade opening. The structure also showed very high vibration levels when operating under maximum load conditions and at a maximum rotation of $42 \mathrm{rpm}$. Therefore, wind intensities in the range of 3 to $12 \mathrm{~m} / \mathrm{s}$ were adopted.

Figure (16) shows the results for power coefficient, $C_{p}$, versus tip-speed ratio $(\lambda)$, from which it is possible to estimate the operational field of the turbine as a function of rotation. From Fig. 14, it is possible to note that the highest power coefficients are found when rotation ranges from 9 to $24 \mathrm{rpm}$. From the curves shown in Fig.17 it is possible to evaluate the behavior of $C_{p}$ as a function of the wind velocity for maximum efficiency conditions. The result is shown in Fig.(18).

Figure 16 shows the evolution of shaft power as a function of wind speed for the DEC $®$ bench tests. It is possible to note a region of instability for lower velocity values, at which the torque mechanism results in many mechanical losses. 
R. G. Ramirez Camacho et al. / JAFM, Vol. 15, No. 2, pp. 603-615, 2022.

Table 2 - Experimental average results, DEC® turbine

\begin{tabular}{|c|c|c|c|c|c|}
\hline \multirow[t]{4}{*}{$\begin{array}{c}\text { Vel. } \\
{[\mathrm{m} / \mathrm{s}]}\end{array}$} & $\begin{array}{l}\text { Torque } \\
\text { N-m }\end{array}$ & $\mathrm{rpm}$ & $\begin{array}{c}\text { Shaft } \\
{[\mathrm{W}]}\end{array}$ & $\lambda$ & $\mathrm{C}_{\mathrm{P}}$ \\
\hline & 3.7060 & 23.254 & 9.024 & 3.943 & 0.185 \\
\hline & 4.1087 & 20.190 & 8.687 & 3.424 & 0.178 \\
\hline & 5.0532 & 18.667 & 9.877 & 3.165 & 0.202 \\
\hline \multirow[t]{7}{*}{3.956} & 5.6294 & 15.035 & 8.863 & 2.549 & 0.181 \\
\hline & 6.1153 & 11.420 & 7.313 & 1.936 & 0.150 \\
\hline & 7.0885 & 7.0510 & 5.234 & 1.195 & 0.107 \\
\hline & 7.1769 & 4.4680 & 3.358 & 0.757 & 0.068 \\
\hline & 4.2717 & 27.984 & 12.51 & 4.568 & 0.229 \\
\hline & 4.8692 & 26.928 & 13.73 & 4.396 & 0.251 \\
\hline & 5.7516 & 23.079 & 13.90 & 3.767 & 0.254 \\
\hline \multirow[t]{7}{*}{4.110} & 6.6009 & 19.250 & 13.30 & 3.142 & 0.243 \\
\hline & 7.8333 & 14.039 & 11.51 & 2.291 & 0.210 \\
\hline & 8.5839 & 9.3920 & 8.443 & 1.533 & 0.154 \\
\hline & 8.5958 & 7.3214 & 6.590 & 1.195 & 0.120 \\
\hline & 5.5588 & 42.222 & 24.57 & 4.049 & 0.091 \\
\hline & 6.4197 & 38.746 & 26.04 & 3.715 & 0.096 \\
\hline & 7.9776 & 33.107 & 27.65 & 3.175 & 0.102 \\
\hline \multirow[t]{7}{*}{7.006} & 9.4451 & 29.448 & 29.12 & 2.824 & 0.108 \\
\hline & 10.8981 & 23.135 & 26.40 & 2.218 & 0.09 \\
\hline & 12.6983 & 12.702 & 16.89 & 1.218 & 0.062 \\
\hline & 12.6152 & 11.761 & 15.53 & 1.128 & 0.057 \\
\hline & -------- & -------- & |-------- & -------- & ------- \\
\hline & -------- & -------- & |-------- & -------- & ------- \\
\hline & 14.776 & 40.444 & 62.58 & 2.468 & 0.059 \\
\hline \multirow[t]{4}{*}{11.002} & 15.068 & 38.119 & 60.14 & 2.326 & 0.057 \\
\hline & 13.3065 & 30.337 & 42.27 & 1.851 & 0.040 \\
\hline & 11.7866 & 15.436 & 19.05 & 0.942 & 0.018 \\
\hline & 10.0951 & 13.563 & 14.33 & 0.827 & 0.013 \\
\hline
\end{tabular}

$\rho=1.18 \mathrm{~kg} / \mathrm{m}^{3}, \mathrm{~A}_{\mathrm{p}}=1.2896 \mathrm{~m}^{2}$

In order to compare the results obtained in the CFD simulation with those obtained in the bench tests, the power coefficient curves are plotted against each other in a single graph. For the calculation of the power coefficient considering the semi-numeric and numerical models in steady regime, the value of the mean of the rotation based on the experimental data is introduced, as shown in Fig.(17).

\subsection{Comparison of DEC® Performance With Other Types of Wind Turbines.}

Given the behavior observed in both the open wind tunnel experiments and the numerical simulations, it would be interesting to compare the studied turbine with commercially available turbines. In order to identify the application field of the DEC ${ }^{\circ}$ wind turbine in comparison with other types of turbine, the dimensionless values of $C_{p}$ and $\lambda$ were used. The result shown in Fig.20 highlights the $C_{p}$ curve as a function of $\operatorname{TSR}(\lambda)$, the black-marked DEC ${ }^{\circledR}$ turbine behaves similarly to the Savonius wind turbine. The maximum $C_{p}$ of 0.25 achieved by the $\mathrm{DEC} \circledast$ turbine is superior to those achieved by Savonius rotors. Therefore, it is concluded that this type of turbine can operate at medium wind velocities.

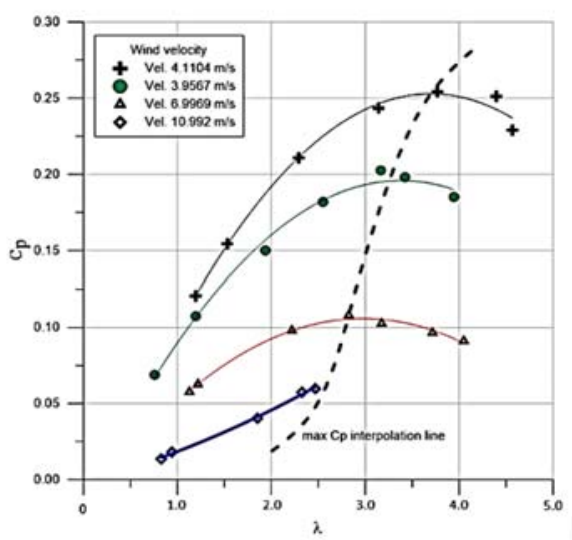

Fig. 16. $C_{p}$ vs. TSR $(\lambda)$ for each wind speed in the DEC $®$ bench test.

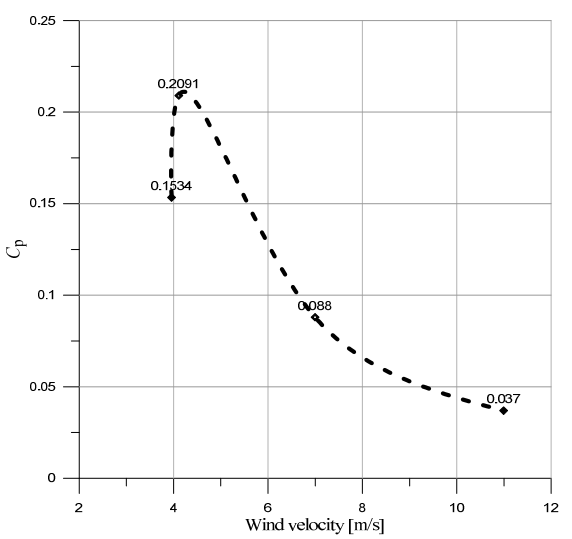

Fig. 17. Power coefficient as a function of wind speed for the DEC ${ }^{\circledR}$ bench tests.

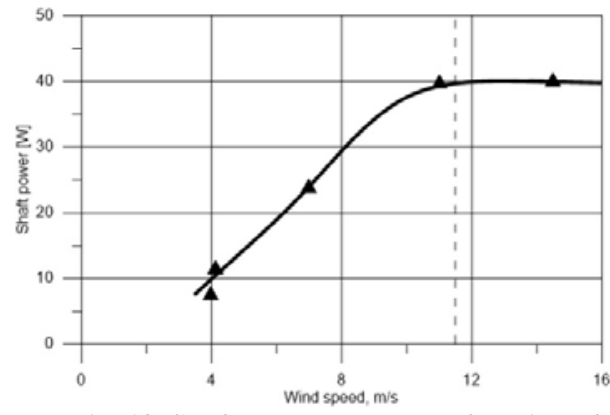

Fig. 18. Shaft power curve as a function of wind speed for the DEC® turbine. 


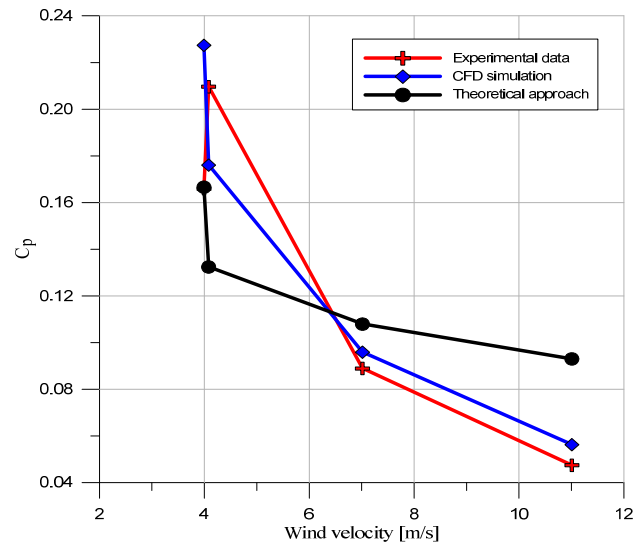

Fig. 19. Comparison between CFD, theoretical and experimental results of $C_{p}$ vs. wind speed.

On the other hand, it is important to note that DEC ${ }^{\circledR}$ turbine, due to the synchronized movement of its blades, has the advantage of an operation with TSR values, greater than that of turbines Savonius and American Wind Turbine (Fig.20), which implies the functionality in power generation systems or mechanical work simple. It was also tested in the experimental test that, with wind intensity around 40 $\mathrm{km} / \mathrm{h}(\sim 11 \mathrm{~m} / \mathrm{s})$, the closing and opening mechanisms of the blades, resulting in displacement severe frequencies that compromise the structural integrity of the model, do not be impossible, in Fig. (20), presenting the behavior of the DEC ${ }^{\circledR}$ in a more extensive way, considering greater intensities of wind.

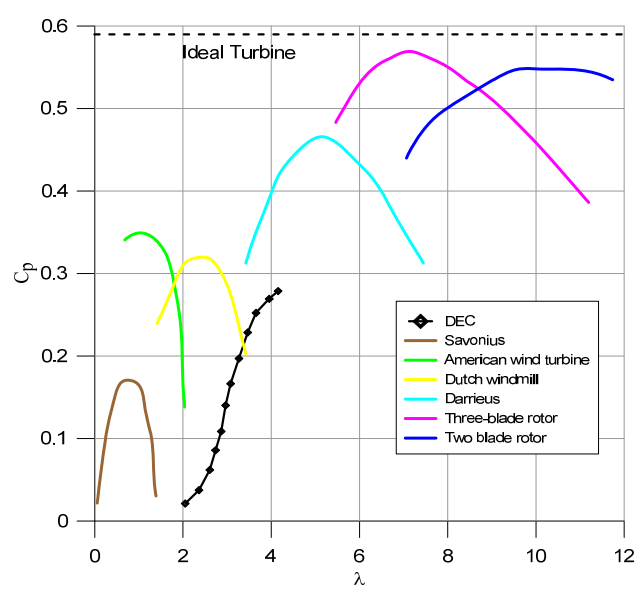

Fig. 20. $C_{p}$ vs. TSR curves for different types of wind turbines.

\section{CONCLUSION}

The experimental test carried out during the development of the present project allowed for a more complete understanding of the new proposed wind energy technology. The results obtained via simulation showed good accordance with those obtained from theoretical and experimental approaches.

The tests presented some obstacles that could have had affected data acquisition, such as the difficulty of analyzing the forces applied to the turbine and the occurrence of mechanical vibrations and noises in the model. On the other hand, the test produced adequate results, and the data-sampling rate was sufficient to evaluate the desired parameters.

The wind turbine showed the self-start capability for winds with speeds of $3.5 \mathrm{~m} / \mathrm{s}$, which is an advantage over other turbines. The DEC ${ }^{\circledR}$ wind turbine reached a maximum $C_{p}$ of 0.25 for a TSR of 4.0 This value was quickly reached for a $4.11 \mathrm{~m} / \mathrm{s}$ wind speed, decreasing as the wind speed increased. These $C_{p}$ and TSR values are valid for a vertical axis wind turbine that operates by impulse, but considering $C_{p}$ vs. TSR variation, the DEC eolic turbine is superior to the Savonius turbine.

Comparing the average $C_{p}$ curve, as a function of the wind speed of the DEC ${ }^{\circledR}$ wind turbine with other types of wind turbines, it can be seen that the DEC ${ }^{\circledR}$ model has particularities in relation to the others, verifying that there is only one wind speed where the turbine it finds its best aerodynamic performance associated with the dynamics of rotational movement and the opening and closing of the blades. For greater wind intensities, the mechanisms must be improved, where the small fold of the blade (Fig.1) has importance in the aerodynamic response.

This can be considered that the performance curve for the DEC ${ }^{\circ}$ power coefficient is greater than the other types of wind turbines, with greater torque; it is possible to conclude that the DEC $®$ model is also superior to other similar ones in terms of power density. When operating at speeds from $12 \mathrm{~m} / \mathrm{s}$, the model presented a high level of vibration, which can damage the structure. In the tests above this speed, the cables in the vane openings were broken and the plates loose from their support rods, making it impossible to perform the tests at these speeds properly.

With the VAWT in operation, the opening and closing movement of the blade plates resulted in high noise levels. The noise occurred mainly due to the impact of one plate against another at the moment that the blade closes. The noise level is such that it might discourage the application of this type of wind turbine in areas near urban centers or other areas nearby humans.

Efficiency results did not justify the number of required pieces to ensure blade plate mobility. At the same time, the complexity of the system could lead to high maintenance requirements with many hours of machine downtime, and high replacement part costs.

Considering the systems of power generation, the DEC $®$ wind turbine can be optimized for a rapid aerodynamic response in the mechanical system further improving torque.

In relation to aerodynamic loads, it is verified that there are variations in the largest increments of wind, 
R. G. Ramirez Camacho et al. / JAFM, Vol. 15, No. 2, pp. 603-615, 2022.

however these can be balanced by piling more rotors in the form of a tower, in order to obtain more uniform torques, improving performance. On the other hand, uniform moments would prevent damage to the variable rotation generator. An evaluation of vibration spectra is necessary to identify the permissible frequency and amplitude levels for continuous operation of the wind turbine. The vibrations analysis would identify the amplitude levels (displacement or velocity) important for the tower dimensioning, as well as the allowable frequency of the aero-mechanical elements for these not to collapse.

Currently, the system of vertical folding blades is being researched, in which the width of each blade and its distance from the axis of rotation can be parameters to be optimized to achieve the highest torque. In this new type of blade opening and closing system, it is important to define how the blade edges should be bent, at its upper and lower corners, to maximize and stabilize the angular momentum. In this sense, numerical methodologies based on boundary element methods and panel methods for the aerodynamic solution in flat plates are being developed for transient analysis including the two degrees of motion, with the advantage of reduced computational cost. Aliabadi and Rasekh (2019), Ramirez Camacho and Manzanares (2005) and Ramirez Camacho R.G. and Barbosa (2008).

\section{ACKNOWLEDGEMENTS}

The authors would like to thank: ANEEL and the Furnas Power Station for the support and resources given in developing this R\&D Project; the Federal University of Itajubá (UNIFEI) for the test platform and research team; the Matrix for project management; to Edicon for making the test model available; to the Teodomiro Santiago Foundation (FTS) for the financial resources and administration provided; and to the National Reference Center for Small Hydroelectric Power Plants (CERPCH), as well as the Virtual Hydraulic Laboratory (LHV).

\section{REFERENCES}

Aliabadi, S. K and S. Rasekh (2019). Effect of sudden change in free stream velocity on the wind turbine airfoil performance based on boundary element method. Engineering Analysis with Boundary Elements. 101, 360370 .

Antonini, E. G. A., D. A. Romero and C. H. Amon (2016). Analysis and modifications of turbulence models for wind turbine wake simulations in atmospheric boundary layers. International Mechanical Engineering Congress and Exposition, IMECE2016. ASME.

Bhutta, M., M. Aslam and M. Hayat (2012) Vertical Axis Wind Turbine - A Review of Various Configurations and Design Techniques. Elsevier, Renewable and Sustainable Energy Reviews 16, 1926-1939.
Ferrari, G., D. Federici, P. Schito, F. Inzoli and R. Mereu (2017) CFD study of Savonius wind turbine: 3D model validation and parametric analysis. Renewable Energy 105, 722-734.

Hui, I, B. E. Cainb and J. O. Dabiri (2018). Public receptiveness of vertical axis wind turbines. Energy Policy 112, 258-271.

Kumar, R., K. Raahemifar and A. S. Fung (2018). A critical review of vertical axis wind turbines for urban applications. Renewable and Sustainable Energy Reviews 89, 281-291.

Launder, B. E. and D. B. Spalding (1974). The Numerical Computation of Tturbulent Flows. Computer Methods in applied mechanics and engineering 3, 269-289.

LEAP CFD TEAM (Blog). Tips \& Tricks: Convergence and Mesh Independence Study. January 17, 2012.

Lee, J. H., Y. T. Lee and H. C. Lim (2016) Effect of twist angle on the performance of Savonius wind turbine. Renewable Energy 89, 231-244.

Letcher, T. M. (2017). Wind Energy Engineering. Academic Press of Elsevier.

Manwell, J. F., J. G. Mcgowan and A. L. Rogers (2009). Wind Energy Explained Theory, design and Aplication. John Wiley and Sons, Chichester, UK.

MCtavish, S., D. Feszty and T. Sankar (2012). Steady and rotating computational fluid dynamics simulations of a novel vertical axis wind turbine for small-scale power generation. Renewable Energy 41, 171-179.

Menter, F. R. (1994). Two-Equation Eddy-Viscosity Turbulence Models for Engineering Applications. AIAA Journal 32 (8), 1598-1605.

Qasim, A. Y., R. Usubamatov and Z. M. Zain (2011). Design of Vertical Axis Wind Turbine with Movable Vanes. Australian Journal of Basic and Applied Sciences 5(11), 896-902.

Ramirez Camacho R. G. and J. R. Barbosa (2008). The boundary element method applied to forced convection heat problems. International Communications in Heat and Mass Transfer 35(1), 1-11.

Ramirez Camacho R. G. and N. Manzanares Filho (2005). A Source Wake Model for Cascades of Axial Flow Turbomachines. Journal of the Brazilian Society of Mechanical Sciences, Vol. XXVII, 288-299.

Wilcox, D. C. (1993). Comparison of Two-equation Turbulence Models for Boundary Layers with Pressure Gradients. AIAA J. 31(8), 1414-1421.

Wilcox D. C. (1994).Simulating Transition with a Two-equation Turbulence Model. AIAA J. 32, $247-255$

Wilcox, D. C. (1988) Reassessment of the Scaledetermining Equation for Advanced Turbulence Models. AIAA J. 26(11), 1299-1310 